LBNL-45819

\title{
Variability of Consumer Impacts from Energy Efficiency Standards
}

\author{
James E. McMahon \\ Xiaomin Liu \\ Energy Efficiency Standards Group \\ Environmental Energy Technologies Division \\ Lawrence Berkeley National Laboratory \\ Berkeley, California 94720
}

As presented at the 2nd International Conference on Energy Efficiency in Household Appliances and Lighting, Naples, Italy, September 27-29, 2000 


\title{
VARIABILITY OF CONSUMER IMPACTS FROM ENERGY EFFICIENCY STANDARDS
}

\author{
James E. McMahon and Xiaomin Liu \\ Lawrence Berkeley National Laboratory
}

\begin{abstract}
A typical prospective analysis of the expected impact of energy efficiency standards on consumers is based on average economic conditions (e.g., energy price) and operating characteristics. In fact, different consumers face different economic conditions and exhibit different behaviors when using an appliance. A method has been developed to characterize the variability among individual households and to calculate the life-cycle cost of appliances taking into account those differences. Using survey data, this method is applied to a distribution of consumers representing the U.S. Examples of clothes washer standards are shown for which 70-90\% of the population benefit, compared to $10-30 \%$ who are expected to bear increased costs due to new standards. In some cases, sufficient data exist to distinguish among demographic subgroups (for example, low income or elderly households) who are impacted differently from the general population.

Rank order correlations between the sampled input distributions and the sampled output distributions are calculated to determine which variability inputs are main factors. This "importance analysis" identifies the key drivers contributing to the range of results. Conversely, the importance analysis identifies variables that, while uncertain, make so little difference as to be irrelevant in deciding a particular policy. Examples will be given from analysis of water heaters to illustrate the dominance of the policy implications by a few key variables.
\end{abstract}

\section{INTRODUCTION}

This paper describes the method for analyzing the economic impacts on individual households of energy efficiency standards for residential appliances. We use the LifeCycle Cost (LCC) of an appliance as a criterion to determine the effect of standards on individual households. LCC captures the tradeoff between the projected post-standard purchase price and operating expense over the life of the appliance.

The method involves replacing the point estimates of average life-cycle cost of appliances with distributions reflecting the whole spectrum of possible costs and the assessed probability associated with each value. The probabilistic modeling approach has emerged as an important and practical tool for risk assessment, mostly driven by the desire to understand the risk level that individuals face in a certain hazardous environmental condition (Finkel 1990). Since each individual's exposure to health hazards varies, risk management schemes have to be designed to reflect the inter-individual variability, that is, what is the likelihood of an individual facing a specific level of risk in a certain 
circumstance. Similarly, the impact of a national energy efficiency standard on consumers will not be the same for all consumers due to differences in their household characteristics, appliance use patterns, energy prices, etc. Therefore the economic impact needs to be assessed at the individual consumers' level so that policymakers are able to gain an insightful view of how the proposed energy efficiency standards would economically affect certain demographic subgroups such as low-income or elderly households.

Since 1996 researchers in the Energy Efficiency Standards Group at LBNL have applied Monte Carlo simulation to the study of energy efficiency standards of appliances in U.S. residential and commercial sectors, such as fluorescent lamp ballasts, clothes washers, water heaters, and central air-conditioning. The Monte Carlo approach has greatly improved research quality and has been adopted as normal practice for the analysis of U.S. energy efficiency standards. As a summary of the on-going research effort, this paper focuses on illustrating two techniques for using input distributions to determine the distribution of impacts on U.S. consumers from proposed standards and to identify the most relevant factors that would affect the outcome. The examples are drawn from residential clothes washer and electric water heater studies, respectively.

\section{METHODOLOGY}

\section{Inter-Individual Variability}

Inter-individual variability is the key to an assessment of the economic impact of energy efficiency standards on individual consumers or a group of consumers. It represents diversity or heterogeneity in a population (people or events) that is irreducible by additional measurements and refers to, in this paper, varying values of consumers' characteristics. The 1993 and 1997 Residential Energy Consumption Surveys (RECS) (DOE 1995, 1999) provide nationally representative samples for most variables related to appliance usage at the individual household level. In addition, RECS provides a framework to implement a probabilistic simulation such that once a household sample is selected according to its weighting, the values of all associated characteristics are used in the calculation so that consistency among variables is maintained.

The RECS data consists of a sample of more than 7,000 households from the population of all primary, occupied residential housing units in the U.S. Each sample household has a weighting factor that accounts for how often a specific household configuration occurs in the general U.S. population based upon the 1990 U.S. Census. The ratio of the weighting factor of a household to the sum of all weighting factors gives a relative frequency for that specific household, on which a probabilistic sampling process is based. The weighted sample is assumed to represent all actual households in the U.S.

The RECS household records contain rich demographic data and energy use information relevant to various residential appliances. Some of these variables illustrate a great deal of variation and ultimately will create the considerable inter-individual variability among the households in terms of energy use of household appliances. For instance, household water 
heater usage has much to do with the number of occupants and their age distribution. RECS provides detailed counts of number of people (from 1 to 12 or more) in each household and their ages.

When a specific variable cannot be obtained directly from RECS, data can be imputed using related RECS variables and external data sources. Based on a relationship between family size and loads of laundry washed per household per year from a survey study (DOE 1998), a new field is created to represent the variability of household clothes washer use.

\section{Determination of Consumers' Net Benefit or Cost}

Economic impacts on individual consumers from possible revisions to U.S. residential appliance energy-efficiency standards are examined using an LCC analysis. LCC is the total consumer expense over the life of an individual appliance, including purchase expense and operating expenses (which includes expenditures for energy and water). Future operating expenses are discounted to the time of purchase, and summed over the life of the appliance. The impact of standards is a combined effect due to a change in the operating expense (usually decreased) and a change in the purchase price (usually increased). The net result, either benefits or costs to the consumer, is the net change in LCC when comparing alternative efficiency levels corresponding to possible new standards to the current base. LCC and change in LCC can be defined by the following equations:

$$
\begin{gathered}
L C C=P+\sum_{t=1}^{n} \frac{O_{t}}{(1+r)^{t}} \\
\Delta L C C=L C C_{\text {standard }}-L C C_{\text {base }}
\end{gathered}
$$

where: $\mathrm{P}=$ Purchase expense $(\$)$,

$\Sigma=$ Sum over year $\mathrm{t}(\mathrm{t}=1,2, \ldots, n$; lifetime of appliance),

$\mathrm{O}_{\mathrm{t}}=$ Annual operating expense $(\$)$,

$r=$ Discount rate.

If the change in LCC ( $\triangle \mathrm{LCC}$ ) is negative, then there is a benefit (net savings) to the consumer; if positive, there is a net cost to the consumer. Based on this criterion, households benefiting from new efficiency standards can be distinguished from those that are bearing a loss. A Monte Carlo simulation is implemented with 10,000 trials using Microsoft Exce ${ }^{\mathrm{TM}}$ in Windows $98^{\mathrm{TM}}$, combined with Crystal Ball ${ }^{\mathrm{TM}}$ (a commercially available add-in program). During the sampling process, household records are selected based on their relative frequency derived from weightings. Those variables from sources other than RECS are simultaneously sampled according to the statistical distributions by which they are defined. Sampled values of the variables are then used in calculating LCC for various efficiency levels and the baseline. The resulting $\Delta$ LCC distribution presents an impact profile of the efficiency standards on U.S. consumers. 
The primary results are depicted in two types of charts: 1) a frequency chart (Figure 1) showing the range of $\triangle \mathrm{LCC}$ values with their corresponding probabilities of occurrence and 2) a cumulative chart (Figure 2), an integral of the frequency distribution, showing the probability that $\triangle \mathrm{LCC}$ will be less than or equal to a certain given value. As illustrated in Figure $2, \operatorname{Prob}(\Delta \mathrm{LCC} \leq 0)=0.79$ indicates that for the $35 \%$ efficiency improvement level of clothes washers, $79 \%$ of household samples will have reduced LCC compared to the baseline.

For those household samples with net savings (negative $\triangle \mathrm{LCC}$ - shown as the shaded area in Figure 1), the 35\% efficiency improvement level of clothes washers provides them reduced operating expense-energy and water-greater than the increased purchased expense. The average LCC reduction for all 10,000 samples is $\$ 242$. The chart shows a range of change in LCC from net savings of $\$ 1250$ to net cost of $\$ 750$ depending on household characteristics such as number of occupants in a family. (The extreme minimum and maximum values are off-scale outliers, and are provided in Table 1).

Since the level of impact of energy efficiency standards varies with different households, certain groups of consumers, such as households with lower income levels, may be disproportionately affected. To evaluate the impacts on any identifiable groups, the simulations are conducted for two subgroups of the population derived from RECS: lowincome and senior. Low-income households are defined as at or below $100 \%$ of poverty level and senior households are those whose household head is over 65 years old. Table 1 shows that low-income households have a slight higher fraction $(80.7 \%)$ that benefits from the $35 \%$ efficiency improvement level than the general population $(79.1 \%)$, while the senior-headed households have a lower (70.6\%) percentage of beneficiaries under the new standard.

\section{Table 1. $\triangle$ LCC (1997 US\$) by Percentiles between the General Population and Subgroups for 35\% Efficiency Improvement Level}

\begin{tabular}{|l|c|c|c|c|c|c|c|c|c|}
\hline Groups & $0 \%$ & $10 \%$ & $25 \%$ & $50 \%$ & $75 \%$ & $90 \%$ & $\begin{array}{c}100 \\
\%\end{array}$ & Mean & $\begin{array}{c}\text { Percent having } \\
\text { net savings } \\
(\Delta \mathrm{LCC}<0)\end{array}$ \\
\hline General & $(2,341)$ & $(663)$ & $(406)$ & $(194)$ & $(33)$ & 111 & 616 & $(242)$ & $79.1 \%$ \\
\hline Low Income & $(2,695)$ & $(773)$ & $(484)$ & $(231)$ & $(43)$ & 100 & 632 & $(289)$ & $80.7 \%$ \\
\hline Senior & $(2,541)$ & $(462)$ & $(263)$ & $(104)$ & $(22)$ & 165 & 640 & $(132)$ & $70.6 \%$ \\
\hline
\end{tabular}

\section{Identification of Most Important Inputs}

The output distribution in Figures 1 and 2 resulting from simulation modeling reflects the variability contributed by all the inputs combined. One needs to understand which of these inputs are key factors in a complicated model that involves many variables. For example, the residential electric water heater life-cycle cost model involves more than 118 input distributions, all represented by statistical distributions (triangular, normal, or useddefined discrete distributions) in five sequential modules (LCC depends on Equipment 
Cost and Operating Cost. Operating Cost depends on Energy Consumption, which depends on Hot Water Use). Calculations in the five modules are carried out simultaneously in a simulation run. The statistical method can help identify which factors play a dominant role in each of the five modules and consequently act as the driving forces influencing the ultimate result, the impact on consumers.

Furthermore, in the case where uncertainty (due to incomplete or insufficient data) is being explicitly addressed in the model, we want to determine which uncertainties merit an investment in additional data collection or analysis so that we can reduce that uncertainty and enhance the model accuracy. Determining which variables are important and which are not will enable us to simplify or improve the model with less effort by focusing only on those few inputs that are most relevant.

To identify the key variables, we use rank order correlation (or Spearman correlation) between each of the input distribution samples and the output distribution. It is measured by using the ranks of the samples, with the largest value assigned a rank of 1 and the smallest, the rank of $n$, to calculate their correlation. By using the ranks of samples, rather than the data values, the correlation is less dependent upon the specific distribution shape (Morgan and Henrion 1990). This method is more robust and more widely applicable to the cases where many different types of distributions are involved.

The importance analyses are conducted for each of the five modules in the electric water heater model with HFC-245fa blowing agent. The results of the importance analysis for the design option of 2.5" insulation, the proposed standard level, are depicted in five charts (Figure 3 to Figure 7, one for each module). The horizontal bars in the charts show the magnitude and direction of each input contributing (positively or negatively) to the output in descending order from the top. It is unambiguously shown that the operating expense-an intermediate result-has the dominant role in affecting the economic impact measured by $\triangle \mathrm{LCC}$ (Figure 3). The operating expense itself is dependent more on the amount of energy consumed than energy prices (Figure 4). Figures 5 and 7 trace back through the model and identify the key primary variables: household composition including number of occupants and their age distribution as well as ownership of other appliances that use hot water such as clothes washers and dishwashers. In this example, the net benefit (or cost) is more dependent on the variability in operating expense than on the variability in equipment costs. On the cost side, Figure 6 shows that markup is the most dominant factor contributing to the variability in consumer equipment costs.

\section{DISCUSSION}

There are two limitations in this study. One is that uncertainty (errors caused by measurement, subjective inference, and model estimation) is not explicitly addressed. For such a large-scale model as that of a water heater, it is very difficult to separate uncertainty from the inter-individual variability for all variables, let alone to quantify them. Therefore, no effort was made to simulate the effect of uncertainty unless we have sufficient information about the error term of a variable. For instance, lifetime of an appliance (e.g., water heaters) is defined as a triangular distribution using the data from a 
industry magazine (DOE 2000). Since no information regarding the accuracy is supplied, the distribution itself is considered to represent only the variability of the appliance's lifetime in U.S. households. When the information about errors is available, we have incorporated error terms into the simulation by using appropriately chosen distributions (e.g., normal distributions representing errors in the estimated hot water draw models by EPRI). Although this mixed treatment of variability and uncertainty could exaggerate the outcome variation (flattening the output distribution), their effects are relatively insignificant compared to those representing the variability. The comparison clearly shows in Figure 7 that water heater inlet temperature (Tin), air temperature (Tair), and thermostat setting (Ttank) have smaller correlation with the output (hot water use) than other variables. And the effects of error terms could be further reduced using a larger number of trials because of the nature of their distributions.

The second limitation is that correlations between some variables have been ignored because of lack of information. As an example, one could infer that, typically, larger families would use more hot water and consequently reduce the water heater lifetime. Since we do not have any information regarding the correlation between household size and water heater life, a lifetime sample is simply randomly matched with a sampled household record.

\section{ACKNOWLEDGMENT}

This work was supported by the Office of Building Research and Standards of the U.S. Department of Energy under Contract No. DE-AC03-76SF00098.

\section{REFERENCES}

Finkel, Adam M., 1990. Confronting Uncertainty in Risk Management: A Guide for Decision-Makers, Resources for the Future, Washington, DC.

Morgan, M. and M. Henrion, 1990. Uncertainty: A Guide to Dealing with Uncertainty in Quantitative Risk and Policy Analysis, Cambridge University Press.

U.S. Department of Energy, Energy Information Administration, 1995. Residential Energy Consumption Survey: Household Energy Consumption and Expenditures 1993. Washington, DC. Report No. DOE/EIA-0321(93).

U.S. Department of Energy, Energy Information Administration, 1999. Residential Energy Consumption Survey: Household Energy Consumption and Expenditures 1997. http://www.eia.doe.gov/emeu/recs/recs97/publicusefiles.html

U.S. Department of Energy, Office of Codes and Standards, 1998. Preliminary Technical Support Document: Energy Efficiency Standards for Consumer Products Clothes Washers. Washington, DC. http://www.eren.doe.gov/buildings/ codes_standards/reports/cwtsd/index.htm

U.S. Department of Energy, Office of Building Research and Standards, 2000. Technical Support Document: Energy Efficiency Standards for Consumer Products: Residential Water Heaters.<http://erendev.nrel.gov/buildings/codes_standards /reports/waterheater/index.html> 


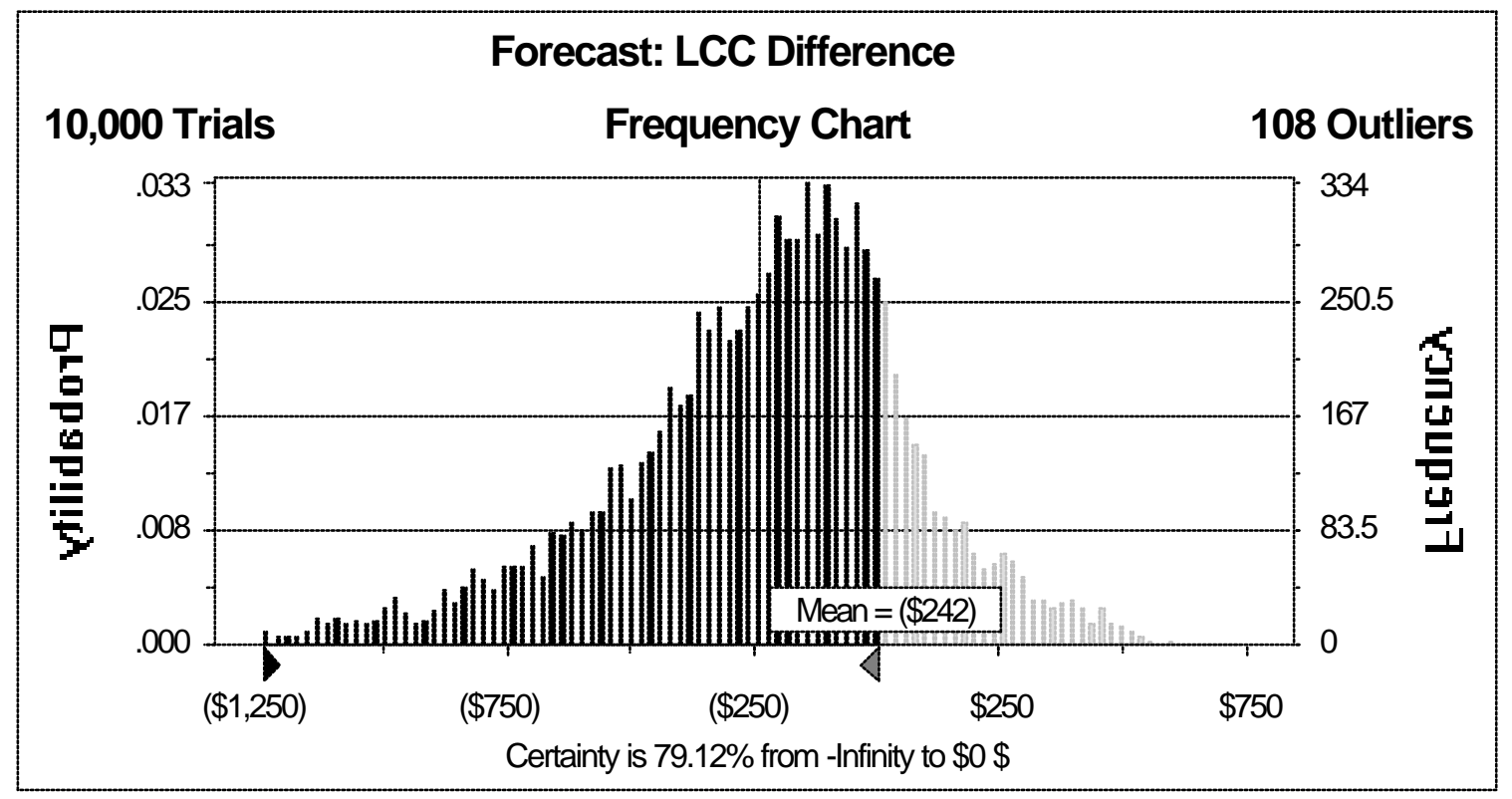

Figure 1. A 35\% Efficiency Improvement in Clothes Washers Will Result in an Average Lifetime Savings of \$242 Per Washer

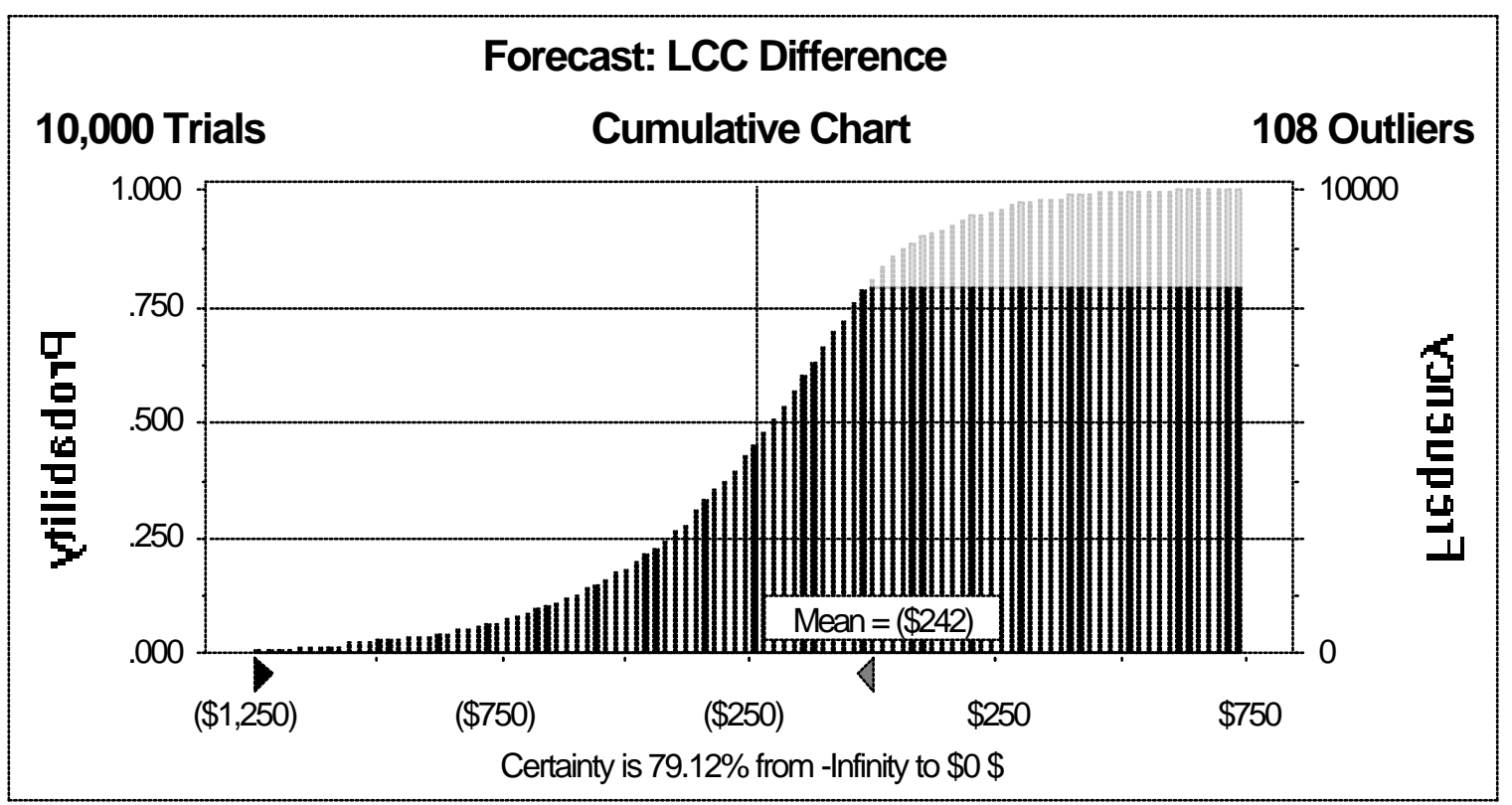

Figure 2. A 35\% Efficiency Improvement in Clothes Washers Will Result in Net Savings for $79 \%$ of Washers 


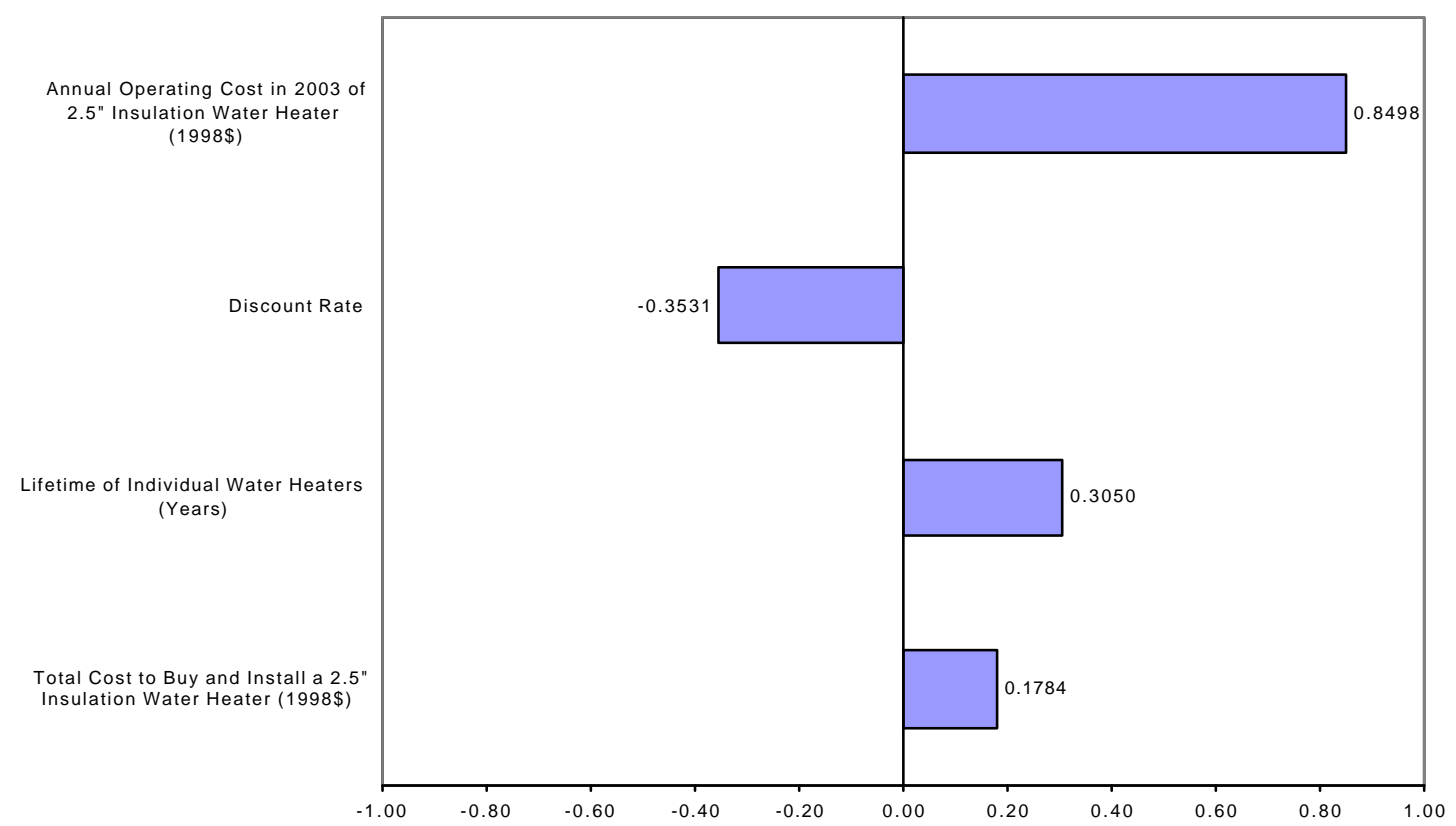

Figure 3. Annual Operating Cost is the Most Important Input Variable to Life-Cycle Cost (for Increasing Insulation to 2.5" on an Electric Water Heater with HFC-245fa)

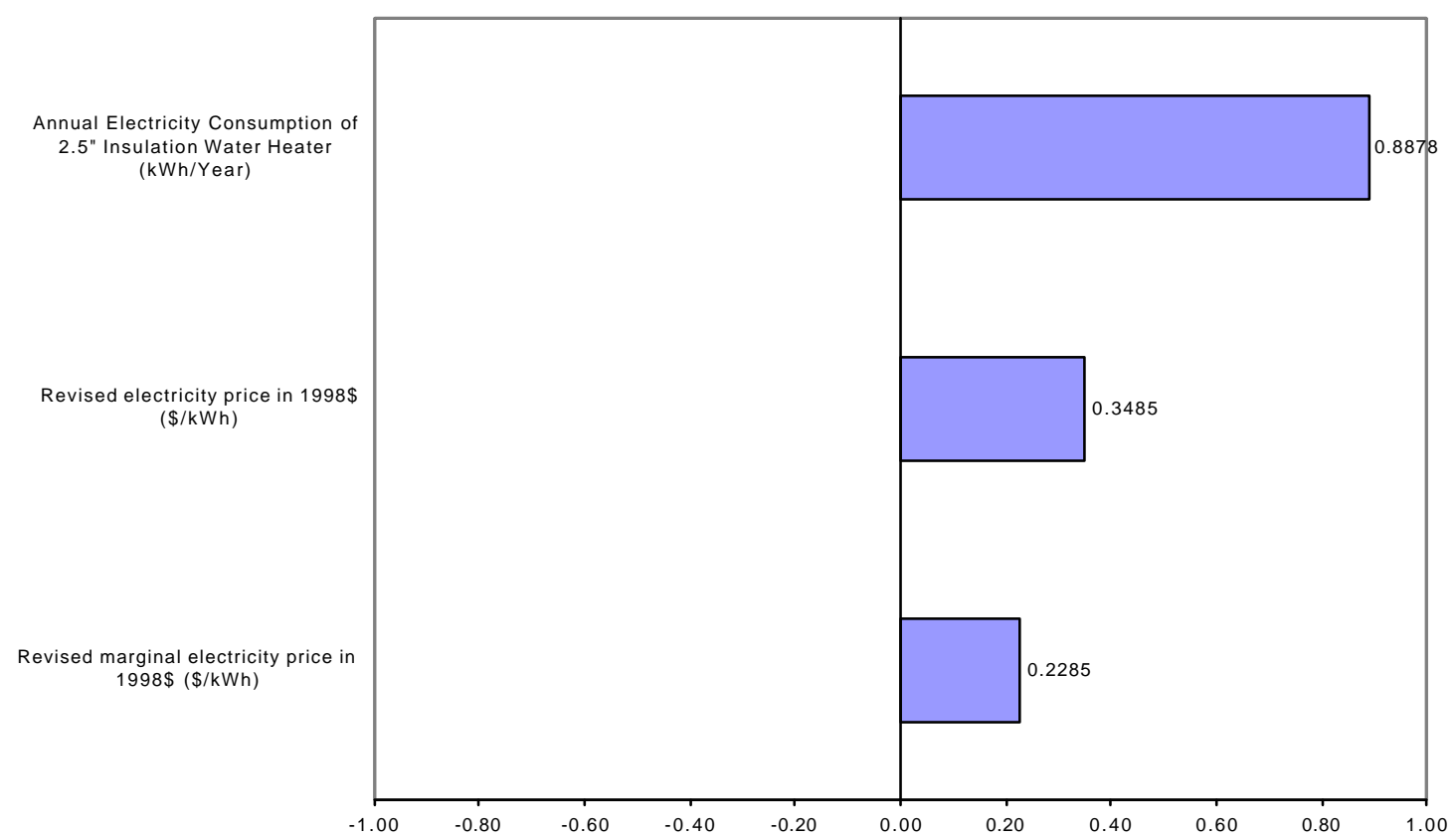

Figure 4. Annual Electricity Consumption is the Most Important Input Variable to Operating Cost (for Increasing Insulation to 2.5' on an Electric Water Heater with HFC-245fa) 


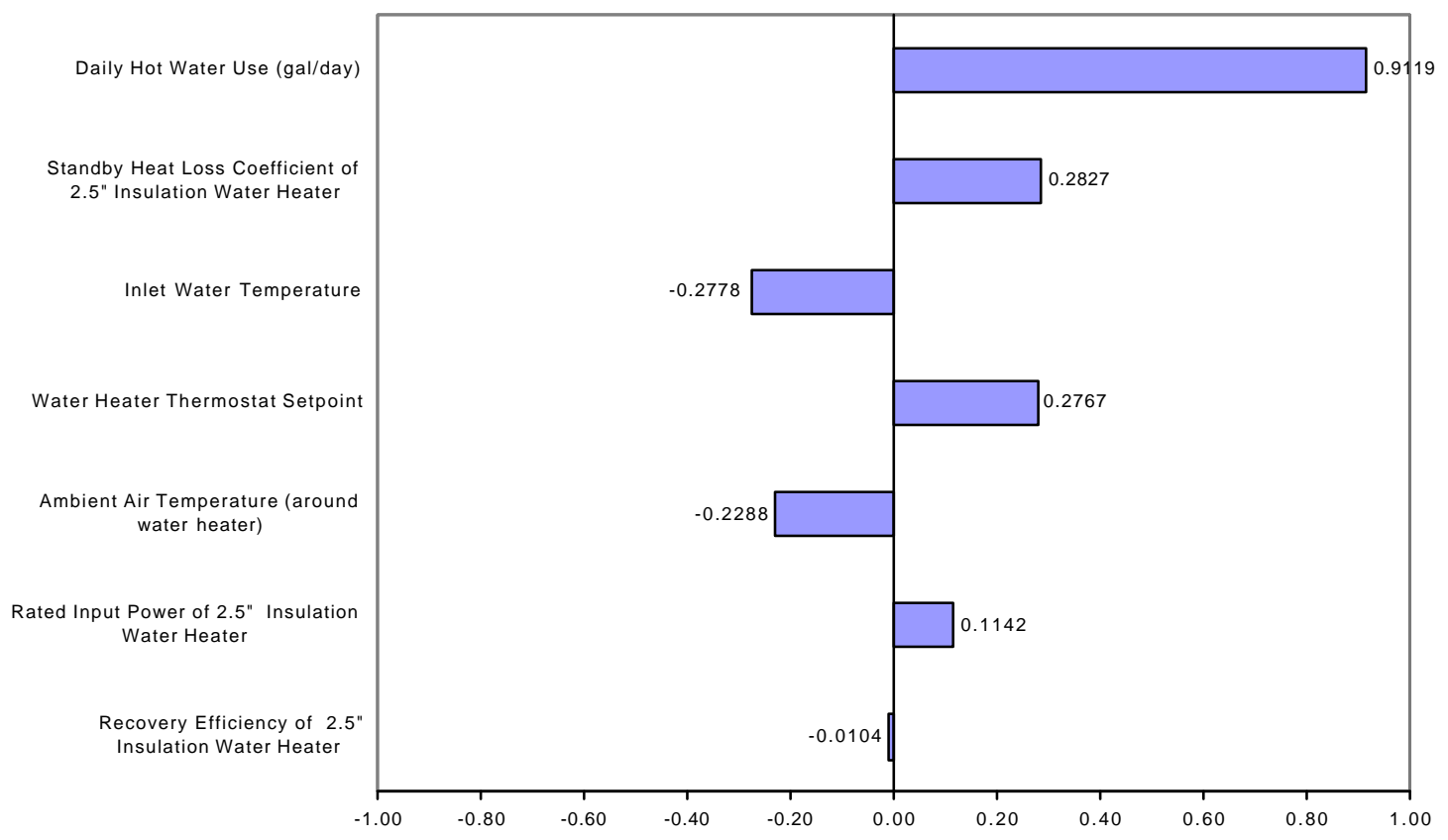

Figure 5. Daily Hot Water Use is the Most Important Input Variable to Annual Electricity Consumption (for Increasing Insulation to 2.5" on an Electric Water Heater with HFC-245fa)

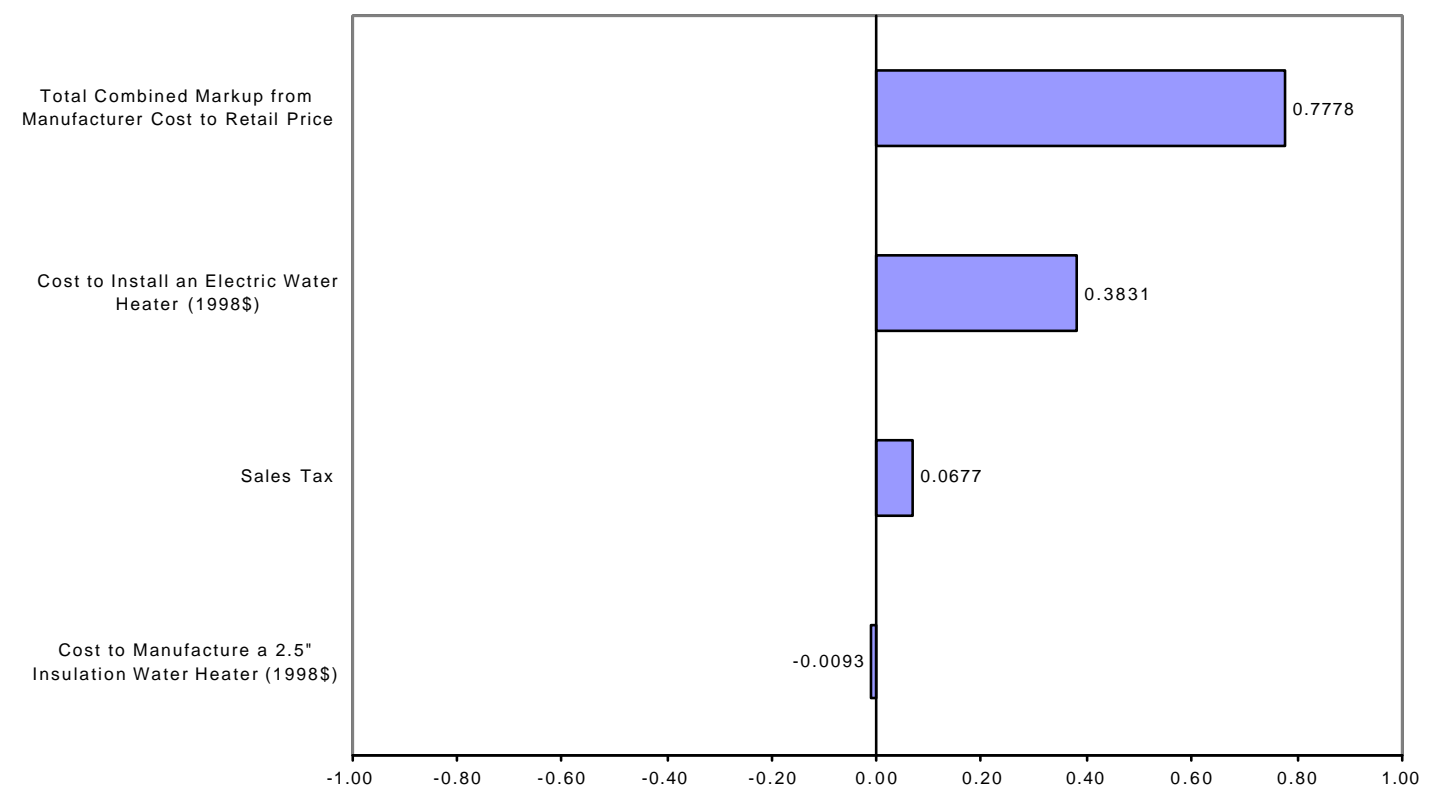

Figure 6. Markup from Manufacturer Cost to Retail Price is the Most Important Input Variable to Equipment Cost (for Increasing Insulation to 2.5' on an Electric Water Heater with HFC-245fa) 


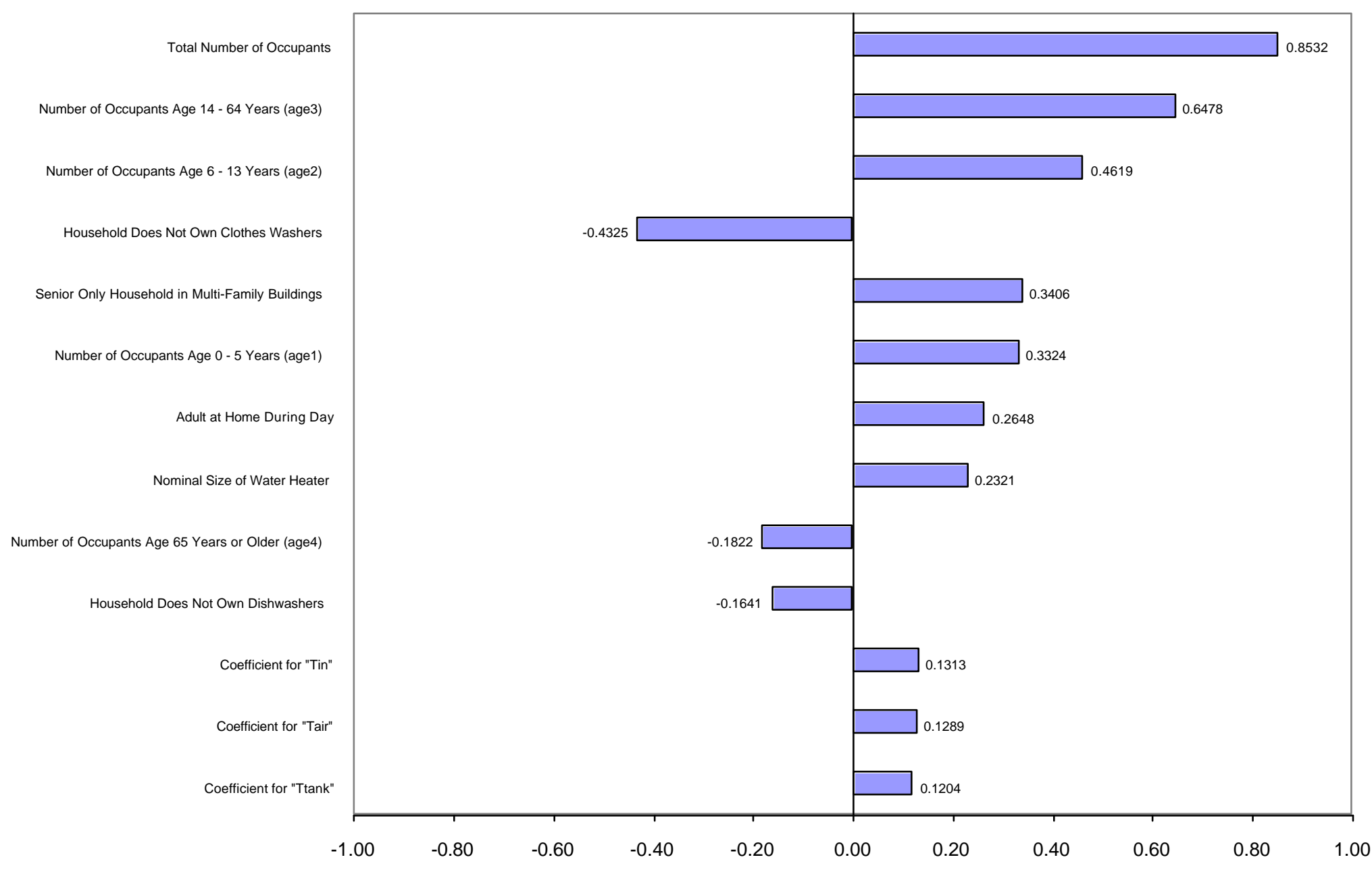

Figure 7. Total Number of Occupants is the Important Input Variable to Hot Water (for Increasing Insulation to 2.5" on an Electric Water Heater with HFC-245fa)

Note: Those inputs with correlation coefficients smaller than 0.1 are not shown on the chart. 